\title{
MATERIAIS PARA O ENSINO E A APRENDIZAGEM DE MATEMÁTICA E OS CENTROS DE VIVÊNCIAS LÚDICAS: OFICINAS PEDAGÓGICAS DA REDE PÚBLICA DE ENSINO DO DISTRITO FEDERAL, BRASIL (1986-2019)
}

Mônica Menezes de Souza SEEDF, COMPASSODF profmonicams@yahoo.com.br

Carmyra Oliveira Batista

SEEDF, COMPASSODF carmyra.batista@gmail.com

Rosália Policarpo Fagundes de Carvalho UDF, SEEDF, COMPASSODF rosaliapolicarpo@yahoo.com.br

Edilene Simões Costa dos Santos

UFMS, COMPASSODF edilenesc@gmail.com

\section{RESUMO}

Neste trabalho objetivou-se apresentar as Oficinas Pedagógicas (OPs) como lócus para produção de materiais de ensino e de aprendizagem e para formação continuada de professores da rede pública do Distrito Federal (DF). Utilizou-se como referencial teórico e para análise de documentos Alferes e Mainardes (2011), Fiscarelli (2008), Gallego e Jiménez (2012) e Souza (2013). Como um dos materiais mais utilizados no trabalho dessas OPs, destacou-se o Tangram e verificou-se os saberes, os valores e os significados construídos em torno de sua utilização. Concluiu-se que as OPs são um espaço permanente e disponível aos professores, mantendo seus cursos alicerçados no fazer manual, com a ludicidade como eixo, sendo provocadoras de autoformação e formação coletiva prático-teórica e experiencial.

Palavras-chave: Oficinas Pedagógicas (OPs). Tangram. Formação continuada de professores.

\section{MATERIALS FOR THE TEACHING AND LEARNING OF MATHEMATICS AND THE LOUD LEARNING CENTERS: PEDAGOGICAL WORKSHOPS OF THE PUBLIC EDUCATION NETWORK OF THE FEDERAL DISTRICT, BRAZIL (1986-2019)}

\begin{abstract}
This paper aimed to present the Pedagogical Workshops (Oficinas Pedagogicas - OPs) as a locus for the production of teaching and learning materials and for the continuing education of public school teachers in the Federal District (DF). It was used as theoretical reference and for document analysis Alferes and Mainardes (2011), Fiscarelli (2008), Gallego and Jiménez (2012) and Souza (2013). As one of the most used materials in the work of these OPs, Tangram stood out and it was verified the knowledge, values and meanings built around its use. It was concluded that the OPs
\end{abstract}


are a permanent space available to teachers, keeping their courses grounded in manual making, with playfulness as the axis, provoking self-training and practical-theoretical and experiential collective formation.

Keywords: Pedagogical Workshop (Oficinas Pedagogicas - OPs). Tangram. Continuing education of teachers.

\section{MATERIALES PARA LA ENSEÑANZA Y EL APRENDIZAJE DE MATEMÁTICAS Y LOS CENTROS DE VIVENCIAS LÚDICAS: TALLERES PEDAGÓGICOS DE LA RED PÚBLICA DE ENSEÑANZA DEL DISTRITO FEDERAL, BRASIL (1986-2019)}

\section{RESUMEN}

Este documento tuvo como objetivo presentar los Talleres pedagógicos (Oficinas Pedagogicas OPs) como un lugar para la producción de materiales de enseñanza y aprendizaje y para la educación continua de los maestros de escuelas públicas en el Distrito Federal (DF). Se utilizó como referencia teórica y para el análisis de documentos Alferes y Mainardes (2011), Fiscarelli (2008), Gallego y Jiménez (2012) y Souza (2013). Como uno de los materiales más utilizados en el trabajo de estos OPs, Tangram se destacó y se verificó el conocimiento, los valores y los significados construidos alrededor de su uso. Se llegó a la conclusión de que las OPs son un espacio permanente disponible para los docentes, que mantienen sus cursos basados en la elaboración manual, con la diversión como eje, lo que provoca la autoformación y la formación colectiva práctica-teórica y experiencial.

Palabras clave: Oficinas Pedagógicas (OPs). Tangram. Formación continuada de profesores.

\section{MATERIELS POUR L'ENSEIGNEMENT ET L'APPRENTISSAGE DES MATHEMATIQUES ET DES CENTRES D'EXPERIENCES LUDIQUES: ATELIERS PEDAGOGIQUES (OFICINAS PEDAGOGICAS) DU RESEAU PUBLIQUE DE L'ENSEIGNEMENT DU DISTRICT FEDERAL, BRESIL (1986-2019)}

\section{RÉSUMÉ}

Cet article avait pour objectif de présenter les ateliers pédagogiques (Oficinas Pedagogicas - OPs) comme un lieu de production de matériel pédagogique et de formation continue pour les enseignants des écoles publiques du District Fédéral (DF). Il a été utilisé comme référence théorique et pour l'analyse de documents Alferes et Mainardes (2011), Fiscarelli (2008), Gallego et Jiménez (2012) et Souza (2013). Tangram a été l'un des éléments les plus utilisés dans le travail de ces OPs et a permis de vérifier les connaissances, les valeurs et les significations construites autour de son utilisation. Il a été conclu que les OPs sont un espace permanent à la disposition des enseignants. Leurs cours sont fondés sur la fabrication manuelle, avec le jeu en tant qu'axe, provoquant l'auto-formation et la formation collective pratique-théorique et expérientielle.

Mots-clés: Ateliers pédagogiques (Oficinas Pedagógicas - OPs). Tangram. Formation continue des enseignants.

Rev. Iberoam. Patrim. Histórico-Educativo, Campinas (SP), v. 05, p. 1-18, e019022, 2019. 


\section{INTRODUÇÃO}

Quando refletimos sobre a escolarização é importante salientar que os processos educacionais estão imbricados em aspectos humanos e materiais. Desse modo, entendemos que os materiais utilizados para a promoção do ensino e da aprendizagem escolar no Brasil estão inseridos em aspectos condicionados aos interesses sociais.

Em levantamento nos Anais dos dois últimos Encontros Nacionais de Pesquisa em História da Educação Matemática (ENAPHEM), cujas temáticas foram "Fontes, temas, metodologias e teorias: a diversidade na escrita da História da Educação Matemática no Brasil” (ENAPHEM, 2014) e "História da Educação Matemática e formação de professores" (ENAPHEM, 2016), constatamos que houve discussão sobre materiais didáticos em pesquisas que tratam da formação de professores e da análise de manuais para ensino; sobre vagas pedagógicas e movimentos educacionais; sobre o ensino de geometria e de aritmética; sobre métodos específicos para o ensino primário; sobre cursos, autores ou manuais que influenciaram a formação de professores em diversos contextos e regiões do país; sobre legislações educacionais, seja identificando-as, seja relacionando-as a determinadas vertentes educacionais ou analisando suas indicações em documentos oficiais.

É nesse contexto de possibilidade diferenciada que apresentamos neste texto um locus de formação continuada de professores da rede pública de ensino do Distrito Federal, Brasil (DF), denominado Centros de Vivências Lúdicas - Oficinas Pedagógicas. Tendo em vista a especificidade desse espaço pedagógico dentro da Secretaria de Estado de Educação do Distrito Federal (SEEDF), questionamos: é possível identificar tendências pedagógicas que nortearam o trabalho das Oficinas Pedagógicas (OPs) ao longo do tempo? As atividades didáticas desenvolvidas nas OPs aliam-se às diferentes propostas pedagógicas presentes nas políticas públicas do DF? Desde a criação das OPs, há registros da utilização e permanência dos materiais produzidos até os tempos atuais, bem como a sua procedência a partir do critério de origem?

Assim, delineamos nosso objetivo que é apresentar as Oficinas Pedagógicas (OPs) como lócus para a produção de materiais de ensino e de aprendizagem e para a formação continuada de professores no Distrito Federal.

Para tratar do tema utilizamos como referencial teórico: Alferes e Mainardes (2011), que tratam da formação continuada no Brasil, além de Fiscarelli (2008), Souza (2013) e Gallego e 
Jiménez (2012), que discutem os materiais de ensino e de aprendizagem a partir de suas finalidades, valores sociais, origem e utilização.

Os documentos que interrogamos para tratarmos do nosso recorte temático foram: a Orientação Pedagógica No 8, elaborada em consonância com o Plano Quadrienal de Educação PQE - 1987/1990 - GDF/SE/FEDF; a Portaria No 388, que trata das atividades desenvolvidas pelos Centros de Vivências Lúdicas - Oficinas Pedagógicas (OP); o documento síntese do I Encontro das Oficinas Pedagógicas; documentos produzidos em 1990 pela Seção de Provimento e Produção do Setor de MEAS ${ }^{1}$, responsável pela coordenação das OPs; e dois catálogos de jogos das OPs, um de 1997 e outro de 2007, no qual estão acondicionados os jogos relacionados ao ensino e à aprendizagem de matemática, dentro dos currículos da educação básica do sistema público de ensino do DF (BRASIL, 1989a; 1989b; 1997; 1998; 1999; 2007; 2018). Portanto, nosso recorte temporal vai de 1986 até os dias atuais.

\section{ASPECTOS TEÓRICO-METODOLÓGICOS}

Alferes e Mainardes (2011) afirmam que as primeiras experiências com a formação continuada datam de 1960 e que, citando Silva e Frade, dentro das três últimas décadas os momentos políticos reconhecidos como ditadura militar, o movimento de redemocratização e os movimentos de globalização da cultura e da economia influenciaram os processos de formação continuada de professores. Ainda conforme os autores, no fim da década de 80 e início da década de 90 do século XX é que houve maior ênfase para a formação do professor em serviço.

No processo histórico, o professor passou a ser compreendido como um trabalhador, um profissional. Portanto, como trabalhador necessita de instrumental para desenvolver seu ofício. Em decorrência da organização que a sociedade foi dando à escolarização ao longo do tempo, o instrumental utilizado pelo professor se modificou e se diversificou.

Fiscarelli (2008, p. 18) apresenta em seu livro Material Didático: discurso e saberes que, na literatura educacional, o uso de objetos pelos professores e alunos com o intuito de ensinar e aprender tem várias nomenclaturas, apontando como as mais usuais: “objetos escolares, recursos audiovisuais, meios auxiliares de ensino, recursos auxiliares, recursos de ensino-aprendizagem,

\footnotetext{
${ }^{1}$ A denominação de MEAs - materiais de ensino e aprendizagem - é utilizada para os materiais produzidos nas OPs. Rev. Iberoam. Patrim. Histórico-Educativo, Campinas (SP), v. 05, p. 1-18, e019022, 2019.
} 
meios materiais, materiais auxiliares, recursos pedagógicos". Para essa autora, todas essas nomenclaturas trazem em si um conceito que vai além de identificar o tipo de material utilizado, pois contêm elementos que se associam às funções básicas deste objeto para o ensino. A autora define material didático como todo ou qualquer material que o professor pode utilizar em sala de aula - desde os mais simples como o giz, a lousa, o livro didático, os textos impressos, até os materiais mais sofisticados e modernos - e, ainda, considera: o conjunto de saberes, valores e significados construídos em volta de um objeto de ensino, fazendo-o útil ao processo de ensino e de aprendizagem, é que o transforma em um material didático.

Outra autora que traz suas contribuições acerca do tema é Souza (2013) em seu artigo Objetos de ensino: a renovação pedagógica e material da escola primária no Brasil, no século $X X$, que buscou analisar o papel dos objetos de ensino nas proposições de renovação da escola primária durante o século em questão, assinalando as mudanças na composição material das escolas. Essa autora sustenta que, a partir do método intuitivo, os meios auxiliares e a passagem da percepção para as ideias foram considerados de fundamental importância no ensino e essa ênfase coincide com o momento em que as sociedades ocidentais começaram a produzir esses materiais escolares pelo processo de industrialização que simbolicamente representava um aspecto da dinâmica civilizatória. Quanto à vaga Escola Nova, a autora mostra que os objetos tornaram-se mediadores da experiência e da atividade. Assim, os recursos materiais perderam a centralidade para a aquisição de conhecimento e passaram a cumprir uma finalidade auxiliar, favorecendo a atividade do estudante. Esse outro fim atrela-se à nova intencionalidade da educação que associa "a escola aos projetos de modernização e reconstrução social do país", segundo Souza (2013, p. 109). Assim, cabia à escolarização conformar a criança às necessidades da sociedade moderna e proporcionar meios para que esta criança fosse um elemento transformador do meio social. A autora discorre também sobre o momento tecnicista da educação, denominado por ela de tecnologia educacional: quanto aos materiais, agora chamados de recursos, há uma ampliação de modalidade, pois são incorporados à educação os recursos audiovisuais como meio de atualizar, modernizar e de tornar mais eficaz à prática educativa. Nesse sentido a autora trata dos saberes, valores e significados ao redor de um objeto de ensino.

Embora Fiscarelli (2008) e Souza (2013) não tenham tratado do uso mais recente dos materiais na escolarização, aventamos a hipótese de que a partir dos decênios de (19)80 e (19)90, devido às discussões sobre questões ambientais - desenvolvimento de uma consciência ecológica

Rev. Iberoam. Patrim. Histórico-Educativo, Campinas (SP), v. 05, p. 1-18, e019022, 2019. 
e à Educação Matemática que busca a formação matemática de todo cidadão, bem como às teorias críticas de currículo e pedagogias críticas, os materiais feitos de sucatas também passaram a ser valorizados como recurso para os processos de ensino e de aprendizagem.

Um quarto trabalho que contribui para a discussão sobre materiais utilizados na escola é o de Gallego e Jiménez (2012) denominado El uso de materiales en la enseñanza de la matemática escolar (1925-1936), que tem por objetivo analisar três manuais adotados em escolas normais com o intuito de identificar quais eram os materiais utilizados e a sua função. Assim, aplicando o critério “origem”, Gallego e Jiménez (2012, p. 188-189) classificam os materiais como:

- Materiais didáticos clássicos - aqueles comercializados, como, por exemplo, mapas, sólidos geométricos, etc.

- Instrumentos de desenho - réguas, esquadros, compasso, etc.

- Materiais de diferentes profissões e artes - materiais que permitem conectar a matemática com a vida.

- Objetos materiais de uso comum - palitos, moedas, botões, etc.

- Materiais didáticos de obras de outros autores ou de visitas a outros centros educativos.

- Materiais didáticos de autoria própria ou adaptados.

Essa classificação nos permitiu considerar os materiais não só por seu escopo pedagógico, mas também pela validade cultural e tecnológica de cada época. Fiscarelli (2008) tratou das nomenclaturas dos objetos utilizados na escola para promover o ensino e a aprendizagem e alertou que os materiais têm uma intencionalidade ligada a discursos de renovação pedagógica e reformas educacionais. Souza (2013) abordou os discursos a respeito de materiais, com o mesmo valor social tratado por Fiscarelli (2008), mas acrescentou que a introdução de novos objetos está ligada a diferentes concepções pedagógicas.

Como Gallego e Jiménez (2012) tratam mais especificamente do uso de materiais de matemática na escola e contribuem para o estudo desse tema ao categorizar a procedência dos materiais tendo por critério sua origem, a partir dessas autoras analisaremos as intencionalidades e concepções da Oficina Pedagógica (OP) assim como a origem de certos materiais por ela produzidos, isto é, jogos utilizados para o ensino e a aprendizagem.

Rev. Iberoam. Patrim. Histórico-Educativo, Campinas (SP), v. 05, p. 1-18, e019022, 2019. 


\section{OS CENTROS DE VIVÊNCIAS LÚDICAS - OFICINAS PEDAGÓGICAS}

As Oficinas Pedagógicas (OPs) tiveram sua origem no projeto Faça você mesmo, em 1986, o qual foi criado por uma professora da educação infantil que percebeu a necessidade de produzir jogos para serem utilizados na sala de aula. Então, alguns professores apoiaram a iniciativa e começaram a se reunir em Taguatinga/DF para confeccionar jogos. (FERNANDES, 2016).

Docentes de várias etapas da Educação Básica começaram a participar do projeto que passou a utilizar as salas de aula de Práticas Industriais, disponíveis em algumas escolas, pois a disciplina havia sido extinta da Secretaria de Estado de Educação do Distrito Federal (SEEDF). Como mais professores passaram a procurar os encontros, resolveu-se mudar o nome do projeto para Oficina Pedagógica (LIMA, 2016).

Em 1987, esse projeto foi incluído no Plano Quadrienal de Educação (SILVA, 2017) e cada uma das Coordenações Regionais de Ensino (CRE) da rede pública de ensino do DF passou a ter uma OP. Assim, os professores que queriam produzir materiais pedagógicos para usar em sala de aula tinham um espaço e orientação para fazê-lo no seu horário de coordenação e, portanto, as OPs atendiam as suas necessidades pedagógicas individuais.

Nos documentos analisados pudemos apurar a ênfase na confecção de materiais de ensino e aprendizagem (MEAs) produzidos nas OPs pelos professores. Porém, devido às muitas demandas profissionais desses docentes, o abandono de materiais inacabados nas OPs foi acontecendo de forma sistemática e esse fato levou a uma reconfiguração desse trabalho, então começou-se a atender as escolas. Dessa forma, o professor passou a ser orientado juntamente com o coletivo da sua unidade de ensino.

Quando a SEEDF instituiu o plano de carreira, para ascender em suas etapas de progressão, o professor precisava apresentar uma determinada quantidade de horas de formação. Outra vez, as OPs reconfiguraram seu trabalho passando a ofertar cursos certificados pelo Centro de Aperfeiçoamento dos Profissionais da Educação (EAPE), além de manter encontros solicitados pelas escolas. Em certa medida, podemos considerar que há uma valorização das OPs enquanto espaço de formação continuada de professores, tendo em vista que a certificação de seus cursos é aceita para a progressão funcional.

Atualmente há uma verba da SEEDF para compra dos suprimentos utilizados na confecção dos MEAs para os cursos. Além disso, há uma coordenação central que orienta os 
trabalhos desenvolvidos por todas as OPs - sendo um total de quatorze no momento - e a coordenação central é realizada pelo Centro de Aperfeiçoamento dos Profissionais da Educação (EAPE) e pela Subsecretaria de Educação Básica (SUBEB); logo, os cursos oferecidos estão em conformidade com as políticas públicas adotadas pela SEEDF.

Os profissionais que atuam nessas OPs - denominados de oficineiros - são professores da SEEDF com experiência docente nos anos iniciais, finais ou no ensino médio que foram se qualificando para trabalhar na produção de MEAs e na formação continuada dos profissionais da educação.

A primeira normatização/sistematização da estrutura e do funcionamento das OPs aconteceu em 1989, na Orientação Pedagógica № 8, elaborada em consonância com o Plano Quadrienal de Educação - PQE - 1987/1990 - GDF/SE/FEDF (BRASIL, 1989a). Em 2018, foi publicada a Portaria $N^{\circ} 388$ que trata das atividades desenvolvidas pelas OPs, as quais, a partir de então, passaram a se denominar Centros de Vivências Lúdicas - Oficinas Pedagógicas. (BRASIL, 2018).

Quanto às intencionalidades e concepções, é possível exclarecer que, devido às diferentes políticas educacionais, às mudanças de currículo e às pesquisas sobre a utilização dos jogos e materiais lúdicos em sala de aula, as OPs deixaram de ser um espaço somente de confecção de materiais e tornaram-se um espaço de formação continuada dos profissionais da educação, tendo como foco metodológico a ludicidade, isto é, a ludicidade como elemento deflagrador das metodologias de formação como avaliam Muñiz, Souza e Ferreira (2014). Desse modo:

Todo o acervo técnico pedagógico de pesquisas, produção e utilização de materiais lúdicos acumulados desde seus primórdios não perdeu valor instrumental, porém, passaram a ser um "meio para" e não um fim em si mesmo. O grande desafio então é utilizá-los não como receitas prescritas para o professor aplicá-las, segundo as dificuldades de aprendizagem dos estudantes, mas, como metodologias voltadas para a promoção de enriquecimento e/ou transformações nas práticas docentes. (MUÑIZ; SOUZA; FERREIRA, 2014, p. 6).

É possível afirmar que o trabalho desenvolvido pelas OPs avançou da produção de materiais para a construção do saber, isto é, o material passou a ser um mediador para a compreensão de conceitos.

Ao analisarmos alguns documentos referentes a cursos e oficinas, compreendemos que as OPs trabalham, desde sua origem, em consonância com os currículos da SEEDF, isto é, atendendo 
aos pressupostos básicos de cada currículo de época; entretanto, mantêm a ludicidade como seu eixo de trabalho.

No decênio de 1980, o tecnicismo ${ }^{2}$ estava em voga no DF; dessa forma, os jogos produzidos nas OPs tinham por objetivo atender as propostas curriculares e as necessidades pedagógicas individuais dos professores, porém os oficineiros já trabalhavam na perspectiva da qualidade do ensino, compreendida naquele momento como autonomia docente e utilização de materiais para o processo de ensino e de aprendizagem e não na perspectiva da eficácia tecnicista, pois o documento síntese do I Encontro das Oficinas Pedagógicas, ocorrido em 1989, reafirma o foco na qualidade do ensino e na aprendizagem a partir da utilização de materiais concretos em sala de aula, tendo em vista que o material era considerado como um facilitador da assimilação do conteúdo programático pelo aluno. (BRASIL, 1989b).

Assim, inferimos que, apesar de fazer um atendimento individualizado do professor, o trabalho das OPs oportunizava a pesquisa, a seleção e a confecção de material adequado às suas necessidades pedagógicas. Deste modo, a melhoria qualitativa passava pela autonomia do professor que podia escolher e produzir o material para atender suas práticas de sala de aula.

O documento síntese do I Encontro das Oficinas Pedagógicas mostra ainda, uma ênfase na utilização do material na sala de aula como possibilidade para a melhoria qualitativa do ensino, o que pressupõe uma ressonância do ensino intuitivo e do Programa de Assistência BrasileiroAmericana ao Ensino Elementar (PABAEE) ${ }^{\mathbf{3}}$, isto é, o material é considerado o centro do ensino.

Em virtude disso, os materiais produzidos pelas OPs apontam para o que Souza (2013) discute como conjunto de saberes, valores e significados em redor de um objeto de ensino, ou seja, há uma ênfase na utilização de materiais para a produção de efeitos desejáveis na educação e as OPs se tornaram no DF um setor especial para a produção e disseminação do uso de MEAs.

Conforme os documentos analisados, de 1988 a 1996 foram realizados eventos denominados de Mostras de materiais de ensino e aprendizagem, que eram uma maneira de as OPs darem visibilidade ao seu trabalho e, possivelmente, mobilizarem a participação dos colegas professores. Entre os documentos, encontramos relatórios de reuniões mensais para a organização do trabalho pedagógico e também de reuniões para estudos do ano de 1990 e constatamos que

\footnotetext{
${ }^{2}$ Segundo Saviani (2005), a pedagogia tecnicista organizou o processo educativo a partir de objetivos operacionais e de pressupostos como a neutralidade científica, a racionalidade, a eficiência e a produtividade.

${ }^{3}$ Acordo assinado pelo Brasil e Estados Unidos, em 1956. Um dos objetivos era formar professores da escola normal. (CARVALHO, 2017).
}

Rev. Iberoam. Patrim. Histórico-Educativo, Campinas (SP), v. 05, p. 1-18, e019022, 2019. 
muitos desses encontros de estudos contaram com a participação de professores do Departamento de Métodos e Técnicas da Faculdade de Educação da Universidade de Brasília (UnB).

Dentre os assuntos discutidos, os que mais chamaram nossa atenção foram: a preocupação para que os MEAs abrangessem a conceituação, e não somente a fixação dos conteúdos; a necessidade de fazer o professor perceber que os MEAs estavam ligados aos aspectos lógico, social e psicológico do conhecimento; a definição de brinquedo e de brincar nas tendências pedagógicas; a importância das OPs como espaço para o professor pesquisar e produzir materiais e a utilização, nos jogos, de desenhos feitos pelas crianças ou professores. Presumimos, então, que a produção de MEAs, por parte do professor, acontecia de forma acompanhada, pensada e planejada pelos oficineiros, os quais buscavam uma fundamentação teórica para a sua prática.

No DF, no ano de 1994, foi reeditada a Orientação Pedagógica № 8, sendo revista e atualizada, e uma nova proposta curricular da SEDF foi colocada em ação para os anos iniciais de escolarização. Assim, foi iniciada a implantação da Escola Candanga: uma lição de cidadania, pressupondo a educação escolar como processo importante da formação humana, fundamentada em discussões teórico-conceituais psicológicas e antropológicas para organizar a escola por fases de formação, e não mais seriação. Sua metodologia estava fundamentada em vivências e situaçõesproblema privilegiando a interdisciplinaridade ${ }^{4}$ e a pedagogia de projetos $^{5}$ (BRASIL, 1998). Conforme constatamos nos documentos, nesse momento, os cursos ofertados pelas OPs passaram a atender a essa proposta curricular, abordando a pedagogia de projetos e a interdisciplinaridade, juntamente com a produção de MEAs.

Nos dois primeiros decênios do século XXI, a rede pública de ensino passou por descontinuidades de propostas curriculares, devido a mudanças partidárias de governos. Porquanto houve mudanças curriculares e conceituais em 2002, 2008, 2010, 2014 e 2018 e as OPs tenham se adequado a essas mudanças, mais uma vez, salientamos, elas não se desprenderam de seu referencial de ludicidade.

\footnotetext{
4 "A interdisciplinaridade é um método de pesquisa e de ensino suscetível de fazer com que duas ou mais disciplinas interajam entre si. Esta interação pode ir da simples comunicação das ideias até a integração mútua dos conceitos, da epistemologia, da terminologia, da metodologia, dos procedimentos, dos dados e da organização da pesquisa" (JAPIASSÚ, MARCONDES, 1996, p. 145).

5 "A pedagogia de projetos visa a ressignificação desse espaço escolar, transformando-o em um espaço vivo de interações, aberto ao real e às suas múltiplas dimensões [...] nessa postura, todo conhecimento é construído em estreita relação com o contexto em que é utilizado, sendo por isso mesmo, impossível separar os aspectos cognitivos, emocionais e sociais presentes nesse processo" (LEITE, 1996, p. 3-4).
}

Rev. Iberoam. Patrim. Histórico-Educativo, Campinas (SP), v. 05, p. 1-18, e019022, 2019. 


\section{O TANGRAM E SUA PERMANÊNCIA NAS OFICINAS PEDAGÓGICAS}

Embora haja, em 2019, quatorze Oficinas Pedagógicas no DF, tivemos acesso a somente dois catálogos de jogos de matemática, um de 1997 e outro de 2007, da OP do Plano Piloto (BRASIL, 1997; 2007). Esses catálogos foram organizados pela coordenação das OPs com o intuito de divulgar e documentar o trabalho realizado. Constavam no catálogo de jogos matemáticos, aproximadamente quarenta jogos, tais como Corrida das formas geométricas, Veritek, Baralho das operações, Tangram e Adivinhando números, entre outros. Nesse sentido, podemos afirmar que esses catálogos foram distribuídos para todas as oficinas.

O catálogo de 1997 apresenta jogos que foram produzidos nas OPs desde sua criação até essa data. O catálogo de 2007, por sua vez, acrescenta novos jogos ao rol do catálogo anterior. Dessa maneira, podemos inferir que os jogos ali contidos atravessaram os vários períodos educacionais do DF. Assim, os jogos dos catálogos perpassaram o tempo, no entanto sua forma de produção foi se modificando de acordo com o material disponível para sua confecção.

Nos documentos a que tivemos acesso verificamos que muitos jogos utilizados pelas OPs são adaptações de jogos comerciais e outros foram criados segundo as necessidades dos docentes. Sendo assim, é possível dizer que os MEAs produzidos nas OPs, de acordo com a classificação da procedência, pelo critério de origem, discutidos por Gallego e Jiménez (2012), advêm de: materiais didáticos clássicos, objetos materiais de uso comum, materiais didáticos de obras de outros autores e materiais didáticos de autoria própria.

Dentre os jogos utilizados, elegemos o Tangram para análise (Figura 01). Sabemos que esse jogo é um quebra-cabeça milenar advindo da China, porém não tivemos indicação de como ele adentrou como recurso de ensino e de aprendizagem na sala de aula nos documentos analisados, pois não há menção de sua origem na educação, apenas sendo detectada a sua utilização e permanência desde os primórdios da OP. Contudo, em uma das apostilas de Tangram encontramos alusão a um especialista americano em quebra-cabeças, chamado Sam Lloyd, como produtor de uma versão desse material, além de referência ao autor Luiz Márcio Imenes. Assim, a procedência do Tangram pode ser classificada como: materiais didáticos de obras de outros autores, conforme categorização apresentada por Gallego e Jiménez (2012).

Rev. Iberoam. Patrim. Histórico-Educativo, Campinas (SP), v. 05, p. 1-18, e019022, 2019. 
Figura 01 - Foto Tangram

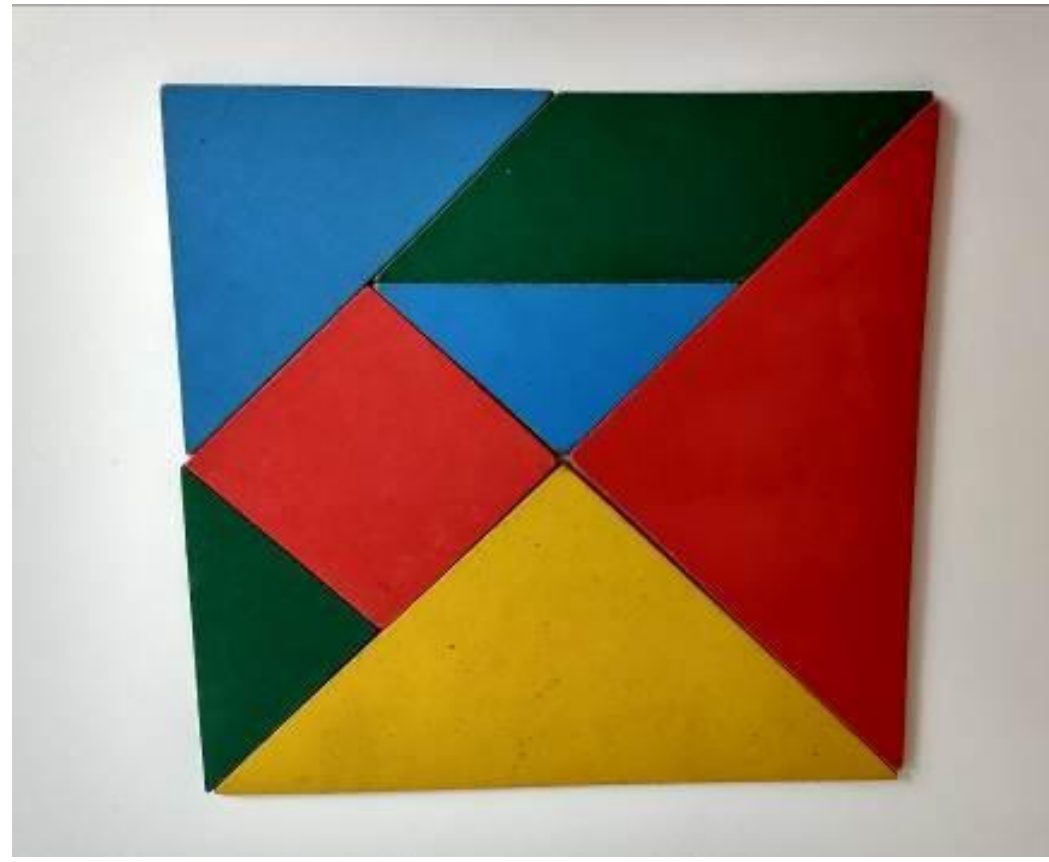

Fonte: Acervo da OP Plano Piloto.

Até 1996 vimos que cada OP fazia o registro de quantos jogos e quantas peças eram produzidas num determinado período, inferindo-se que os jogos, incluindo o Tangram, eram produzidos independentemente de cursos. Ainda, a partir de 1995 o Tangram foi encontrado como material produzido em cursos.

A OP do Plano Piloto ofereceu em 1995 e 1996 cursos para professores de matemática que trabalhavam de $5^{\mathrm{a}}$ a $8^{\mathrm{a}}$ séries e neles o Tangram foi confeccionado e utilizado para abordar conceitos geométricos, além do estudo de números decimais.

Em 1997, encontramos a utilização do Tangram em outro curso também destinado aos professores de $5^{\mathrm{a}}$ a $8^{\mathrm{a}}$ séries. No projeto desse curso a OP do Plano Piloto apresenta uma preocupação com o estudante que chega à $5^{\mathrm{a}}$ série:

A formação do professor está presa a uma perspectiva da matemática pura, abstrata, desvinculada da realidade e dos interesses dos alunos. O livro didático e o livro didático e o quadro-negro, costumam ser os únicos recursos usados em sala de aula, reduzindo de forma importante as possibilidades de vivências significativas tão necessárias para que flua o processo de aprendizagem. O aluno, por sua parte, ao ingressar na 5a. série, é levado a crer que já não tem "direito" às atividades lúdicas de "quando era criança", e que, agora, tudo "é sério"! No entanto, sabemos que o ensino de matemática pode e deve ser atraente, prazeroso. Nesse sentido, o jogo é apresentado como um rico instrumento de mediação. (BRASIL, 1997).

Rev. Iberoam. Patrim. Histórico-Educativo, Campinas (SP), v. 05, p. 1-18, e019022, 2019. 
Nessa perspectiva, para as OPs, o jogo é considerado como um recurso importante também para o processo de ensino e de aprendizagem dos anos finais do ensino fundamental, pois auxilia na construção do conhecimento fazendo com que os estudantes saiam do modus operandis passivo para a interatividade e seu protagonismo. Por conseguinte, nesse momento, o enunciado das OPs aproxima-se da discussão de Souza (2013) sobre os pressupostos da Escola Nova em que os materiais cumprem a finalidade de auxiliar a atividade do estudante.

No curso denominado Na prática a teoria é outra? oferecido em 1999 e destinado aos professores dos anos iniciais do ensino fundamental, o Tangram foi utilizado para trabalhar as figuras geométricas planas. Um dos objetivos específicos desse curso era "promover e fundamentar a formação da concepção de 'jogo pedagógico' e sua contribuição para a construção do conhecimento e formação integral do ser humano" (BRASIL, 1999, p. 3). Mais uma vez podemos inferir que as OPs enfatizavam a importância dos MEAs para o ensino e a aprendizagem, assinalando a permanência das ideias relativas ao material concreto impressas no PABAEE, tendo em vista que nesta perspectiva os objetos de ensino eram auxiliares da atividade do aluno. Portanto, a seleção de materiais era devido a sua potencialidade para estimular a atividade e o interesse do estudante favorecendo as experiências de aprendizagens.

Também encontramos o registro de estudos realizados pelos oficineiros de todo o DF, visando oferecer um curso destinado aos professores dos anos finais do ensino fundamental utilizando o Tangram. Ainda em 1999, foram oferecidas oficinas temáticas e minicursos de Tangram. As oficinas temáticas eram encontros de três horas de duração, realizados no dia de coordenação do professor, e os minicursos tinham a duração de seis horas, porém não há registro de como o Tangram foi utilizado nessas atividades.

Em 2001 foi ofertado o curso Tangram e Mosaicos Geométricos e repetido em 2003 especificamente para os oficineiros. A fundamentação teórica deste curso era baseada em Kamii (sem referência na apostila), Kishimoto (1998), Imenes e Lellis (1997) e os Parâmetros Curriculares Nacionais - PCN (BRASIL, 1998), constando nos documentos do curso que "as atividades com o Tangram propiciam introdução, desenvolvimento, fixação, revisão e avaliação de conteúdos de diversos níveis"; além disso, assevera-se que o jogo, na vida escolar ou fora dela, possibilita estruturação do pensamento, interação social desenvolvendo autonomia e autoconfiança. Esses documentos e análises reforçam a ideia da ênfase dada ao jogo na formação humana.

Rev. Iberoam. Patrim. Histórico-Educativo, Campinas (SP), v. 05, p. 1-18, e019022, 2019. 
Observamos, a partir daí, uma lacuna documental de 2002 a 2011, sendo novamente o Tangram utilizado no ano de 2012 em um atendimento para professores do Colégio Militar de Brasília (CMB) e em um atendimento para orientadoras educacionais do Plano Piloto. Foram vivenciadas e discutidas a sua utilização na dinâmica da fala/escuta, que envolve a clareza, a atenção, a observação e a concentração no ato de comunicar, e as possibilidades do seu uso no ensino e aprendizagem na matemática. Também em 2016, o Tangram foi utilizado em um curso de Origami tanto para os oficineiros como para os profissionais da educação e em oficinas temáticas, oferecidas aos professores do Programa DF Alfabetizado, cuja atividade objetivou: a construção e identificação das principais características de algumas figuras geométricas planas; a exploração de perímetro, área e o estabelecimento de relações fracionárias entre as partes e o todo.

Nosso intento nesta seção foi mostrar a utilização do Tangram em cursos relacionados ao ensino e a aprendizagem da matemática nas OPs, mas sabemos que este material foi e é empregado também em oficinas, cursos e nas práticas dos professores, principalmente dos anos iniciais, para produção de textos, contação de histórias e para o trabalho artístico.

Os documentos coligidos nos permitem dizer que o Tangram é ainda um MEA bastante utilizado para o trabalho com a formação continuada de professores da rede pública de ensino do DF e que, ao longo dos anos de existência das OPs, são os professores de anos iniciais aqueles que mais procuram seus cursos e recursos, porém foram os cursos sobre o Tangram que mobilizaram os professores dos anos finais do ensino fundamental a procurarem as OPs como espaço de formação continuada e em serviço.

\section{CONSIDERAÇÕES FINAIS}

Neste artigo tivemos por objetivo apresentar as Oficinas Pedagógicas (OPs) como lócus para a produção de materiais de ensino e de aprendizagem e para a formação continuada de professores da rede pública de ensino do Distrito Federal.

Nossa problematização girou em torno de identificar no trabalho das Oficinas Pedagógicas (OPs): tendências pedagógicas que o nortearam, possível alinhamento às propostas pedagógicas presentes nas políticas públicas do DF, registros da utilização e permanência de algum material produzido até os tempos atuais, bem como a sua procedência a partir do critério de origem.

Como dissemos ao longo do texto, é possível inferir que: 
- as OPs enfatizavam a importância dos MEAs para o ensino e a aprendizagem, assinalando a permanência das ideias relativas ao material concreto impressas na vaga intuitiva e no PABAEE até o final do decênio de1990 e Escola Nova, após o ano 2000, quando o material passou a ser um mediador para a compreensão de conceitos.

- a longevidade das OPs no sistema público de ensino do DF se deveu a sua capacidade de moldar seu trabalho às políticas educacionais locais e nacionais, porém assegurando aos professores um espaço/tempo de atenção, de ludicidade, de acolhimento e de reflexão sobre suas práticas.

- O Tangram foi um material produzido e utilizado nas OPs em oficinas, cursos e nas práticas dos professores, principalmente dos anos iniciais, para produção de textos, contação de histórias, para o trabalho artístico ao longo de todos esses anos.

- os MEAs produzidos nas OPs, de acordo com a classificação da procedência, pelo critério de origem, discutidos por Gallego e Jiménez (2012), advêm de: materiais didáticos clássicos, objetos materiais de uso comum, materiais didáticos de obras de outros autores e materiais didáticos de autoria própria.

Ao discorrermos sobre um lugar específico de formação que não está configurado como uma escola, um centro de formação ou uma universidade, e sim como um "projeto" que se torna depois um "centro de vivências", percebemos que os nomes carregam em si uma relação entre uma representação e uma possibilidade de ser/estar. Assim, pelo que expusemos, as OPs se tornaram um "projeto concreto", a materialização de um intento, um sonho e, depois de elas serem denominadas como centro de vivências, o trabalho realizado nas OPs indicou uma centralidade não só no processo de ensino, mas no de aprendizagem, de maneira que o trabalho em sala de aula possa ser uma manifestação do estar vivo, ou seja, a sala de aula como espaço/tempo de construção, de pensamento de experiência e de interação.

Ainda é possível dizer que as OPs são um espaço permanente e disponível aos professores da rede pública de ensino do DF de formação continuada e em serviço, provocadoras de autoformação e formação coletiva prático-teórica e experiencial.

Sendo a ludicidade o eixo do trabalho das OPs, permitiu-nos compreender que há uma constante invocação ao trabalho escolar como sentido para a vida, um trabalho humanizador. Também é possível afirmar que as OPs mantiveram seus cursos e oficinas alicerçadas no fazer

Rev. Iberoam. Patrim. Histórico-Educativo, Campinas (SP), v. 05, p. 1-18, e019022, 2019. 
manual, pois constatamos nos documentos analisados a ausência de Tecnologias de Informação e Comunicação (TIC). Outra permanência constatada foi a de nomenclatura dos materiais de ensino e aprendizagem - MEAs - que aparece desde o primeiro documento das OPs até os documentos dos dias atuais.

No trabalho das OPs, com relação ao Tangram, os saberes, valores e significados construídos em torno de sua utilização foram vinculados não somente ao desenvolvimento de conteúdos específicos do ensino e aprendizagem de matemática, mas também a questões vivenciais de comunicação e ao prazer da descoberta.

Mesmo com o movimento de supervalorização ou desvalorização de MEAs no trabalho escolar, o que talvez afiance a longevidade das OPs no sistema público de ensino do DF seja a sua capacidade de moldar seu trabalho às políticas educacionais locais e nacionais, porém assegurando aos professores um espaço/tempo de atenção, de ludicidade, de acolhimento e de reflexão sobre suas práticas.

\section{REFERÊNCIAS}

ALFERES, Marcia Aparecida; MAINARDES, Jefferson. A formação continuada de professores no Brasil. Seminário de Pesquisa do PPE. Universidade Estadual de Maringá, 2011. Disponível em: http://www.ppe.uem.br/publicacoes/seminario_ppe_2011/pdf/1/001.pdf. Acesso em: 01 fev. 2019.

BRASIL. Parâmetros Curriculares Nacionais - Introdução e Terceiro e Quarto ciclos do Ensino Fundamental - Matemática. Brasília: MEC/SEF, 1998. 148 p.

BRASIL. Secretaria de Estado de Educação. Catálogos de jogos das Oficinas Pedagógicas. 1997.

BRASIL. Secretaria de Estado de Educação. Catálogos de jogos das Oficinas Pedagógicas. 2007.

BRASIL. Secretaria de Estado de Educação. Curso Na prática a teoria é outra? Oficinas Pedagógicas. 1999.

BRASIL. Portaria $\mathbf{n}^{\mathbf{0}}$ 388, de 29 de novembro de 2018. Dispõe sobre as atividades desenvolvidas pelas Oficinas Pedagógicas (Centros de Vivências Lúdicas - Oficinas Pedagógicas) da Rede Pública de Ensino do Distrito Federal e dá outras providências. Disponível em: http://www.planejamento.gov.br/assuntos/orcamento-1/orcamentosanuais/2018/legislacao/alteracoes/portaria-mp-no-388-de-29-de-novembro-de-2018.pdf/view. Acesso em: 15 dez. 2018. 
BRASIL. Secretaria da Educação do Distrito Federal. Fundação Educacional do Distrito Federal. Departamento Geral de Pedagogia. Orientação Pedagógica No 8. 1989a.

BRASIL. Secretaria da Educação do Distrito Federal. Documento Síntese do I Encontro das Oficinas Pedagógicas. 1989b. mimeo.

BRASIL. Secretaria de Educação. Fundação Educacional. Lugar da criança é na escola. Balanço de quatro anos do Governo Democrático e Popular na Educação. 1998.

CARVALHO, Rosália P. F. A aritmética no ensino primário de Brasília: 1957-1970. 2017. 226 f. Tese (Doutorado em Educação Matemática) - Universidade Anhanguera de São Paulo. Disponível em: https://repositorio.ufsc.br/handle/123456789/183575?show=full. Acesso em: 15 out. 2019.

ENAPHEM - Encontro Nacional de Pesquisa em História da Educação Matemática, 2., 2014. Anais [...]. Disponível em: https://repositorio.ufsc.br/handle/123456789/135307. Acesso em: 15 dez. 2018.

ENAPHEM - Encontro Nacional de Pesquisa Em História da Educação Matemática, 3., 2016, São Mateus, ES. Anais [...]. Disponível em: https://repositorio.ufsc.br/handle/123456789/171651. Acesso em: 15 dez. 2018.

FERNANDES, Maria Eunice. Entrevista. [2016]. Oficinas pedagógicas - 30 anos. Disponível em: https://www.youtube.com/watch?v=4dnq3gMW3lk\&t=145s. Acesso em: 27 jan. 2019.

FISCARELLI, Rosilene B de O. Material didático: discurso e saberes. São Paulo: Junqueira \& Marin, 2008.

GALLEGO, Dolores C.; JIMÉNEZ, Encarna S. El uso de materiales en la enseñanza de la matemática escolar (1925-1936). In: Foro Ibérico de Museísmo Pedagógico - V Jornadas Científicas de la SEPHE, 3., 2012. Anais [...]. Disponível em: http://congresos.um.es/fimupesephe/fimupesephe2012/paper/viewFile/15021/11991. Acesso em: 10 jan. 2019.

IMENES, Luiz Márcio; LELLIS, Marcelo. Matemática 6 e e $7^{\mathbf{a}}$ séries. São Paulo: Scipione, 1997.

JAPIASSÚ, Hilton, MARCONDES, Danilo. Dicionário básico de filosofia. 3. ed. Rio de Janeiro: Jorge Zahar, 1996.

KISHIMOTO, Tizuko M. O brincar e suas teorias. São Paulo: Pioneira, 1998.

LEITE, Lúcia Helena Alvarez. Pedagogia de projetos. Revista Presença Pedagógica, v. 2, n. 8, mar./abr. 1996. 
LIMA, Ruiter. Entrevista. [2016]. Oficinas pedagógicas - 30 anos. Disponível em: https://www.youtube.com/watch?v=4dnq3gMW3lk\&t=145s. Acesso em: 27 jan. 2019.

MUÑIZ, Elza Lúcia M.; SOUZA, Mônica Menezes de; FERREIRA, Cristina de Fátima F. Oficinas pedagógicas da SEEDF: espaço lúdico de formação continuada de professores. In: Congresso Luso Brasileiro da História da Educação - COLUBHE, 10., 2014. Anais [...].

SAVIANI, Dermeval. As concepções pedagógicas na História da Educação Brasileira. Projeto 20 anos do Histedbr. 2005. Disponível em: http://www.histedbr.fe.unicamp.br/navegando/artigos_pdf/Dermeval_Saviani_artigo.pdf. Acesso em: 14 out. 2019.

SILVA, Maria José de Aragão Capdeville. Oficinas Pedagógicas na história: um espaço de construção da ludicidade na educação do Distrito Federal. Revista Com Censo Brasília, Revista RCC\#10, Brasília: SEEDF, v. 4, n.10, p. 79-82, jun. 2017.

SOUZA. Rosa de Fátima. Objetos de ensino: a renovação pedagógica e material da escola primária no Brasil, no século XX. Educar em Revista, Curitiba: Editora UFPR, n. 49, p. 103120, jul./set. 2013. Disponível em: http://www.scielo.br/pdf/er/n49/a07n49.pdf. Acesso em: 20 jan. 2019.

Recebido em: 20 de maio de 2019

Aceito em: 26 de outubro de 2019 